\title{
Syringomyelia Fluid Dynamics and Cord Motion Revealed by Serendipitous Null Point Artifacts during Cine MRI
}

(D) C.M. Honey, K.W. Martin, and (D) M.K.S. Heran

\begin{abstract}
SUMMARY: Dynamic MR imaging was used to evaluate a cervical syrinx in an adolescent boy with an associated hindbrain herniation. Null artifacts were present on one of the sequences that allowed simultaneous high-resolution visualization of syrinx fluid motion and the anatomy of the syrinx walls. A brief review of the theories of syrinx formation and propagation is provided with a comment on why the Williams "slosh" theory of syrinx progression is supported by our unique imaging.
\end{abstract}

"S yringomyelia" was originally coined by Ollivier $^{1}$ in 1827 and has come to be defined as a tubular cavitation of the spinal cord extending over many segments. ${ }^{2}$ A variety of conditions may cause syringomyelia, including hindbrain herniations, trauma, arachnoiditis, and tumors. ${ }^{3}$ Many different theories have been advanced to explain their cause and growth. ${ }^{4,5}$ The more modern theories all revolve around abnormal fluid dynamics within the spinal canal. MR imaging sequences, which can visualize and measure CSF flow, have been used to elucidate the pathophysiology underpinning syringomyelia. ${ }^{6}$ Unfortunately, these sequences often trade anatomic detail for quantification of CSF movement. During the investigation of a case of syringomyelia associated with a Chiari I malformation, the patient was imaged with dynamic cine balanced steady-state free precession sequences. ${ }^{7}$ Unexpected null artifacts were present that placed a band of low signal through the middle of the syrinx. The dephased water protons could then be visualized as they moved during the cardiac cycle. We describe this hydrodynamic motion of the syrinx fluid and the associated movements of the surrounding spinal cord walls and briefly review the various theories of syrinx formation and growth.

\section{MATERIALS AND METHODS}

A 17-year-old adolescent boy with an asymptomatic C5-6 syrinx detected during screening for a known Chiari I malformation was studied with dynamic MR imaging. ${ }^{7}$ Sequences included a cardiac-gated cine balanced steady-state free precession study on a 1.5T scanner (Intera; Philips Healthcare, Best, the Netherlands). Images were viewed in a video loop to correlate any motion with the cardiac cycle.

\section{RESULTS}

Examples of the sagittal cine MR imaging with and without the null artifacts ${ }^{8}$ are presented in On-line Videos 1 and 2, respectively. During systole, the cerebellar tonsils descended. At the same time, the dilated spinal cord walls surrounding the superior portion of the syrinx collapsed. Within the syrinx, a jet of fluid then moved rostral to caudal, hitting and dilating the inferior walls of the syrinx. During diastole, the syrinx fluid then "sloshed" rostrally, re-expanding the superior walls and allowing the inferior walls to recoil.

Representative diagrams highlighting the spinal cord wall motion and syrinx fluid pulsation at rest (Fig 1A), during systole (Fig $1 B$ ), and during diastole (Fig $1 C$ ) are presented.

\section{DISCUSSION}

The mechanisms causing and enlarging syringes may be different, but most authors have considered them together. Early theories favored a congenital or neoplastic origin. ${ }^{3}$ Gardner and Angel ${ }^{4}$ popularized the "hydrodynamic theory." In patients with a hindbrain abnormality obstructing CSF egress from the fourth ventricle, they postulated that fluid was pushed down into the central canal of the cord, dilating the canal to produce a syrinx. Williams ${ }^{5}$ argued that these mechanisms should cause hydrocephalus not hydromyelia. He measured pressure gradients of $>100 \mathrm{~mm} \mathrm{Hg}$ 

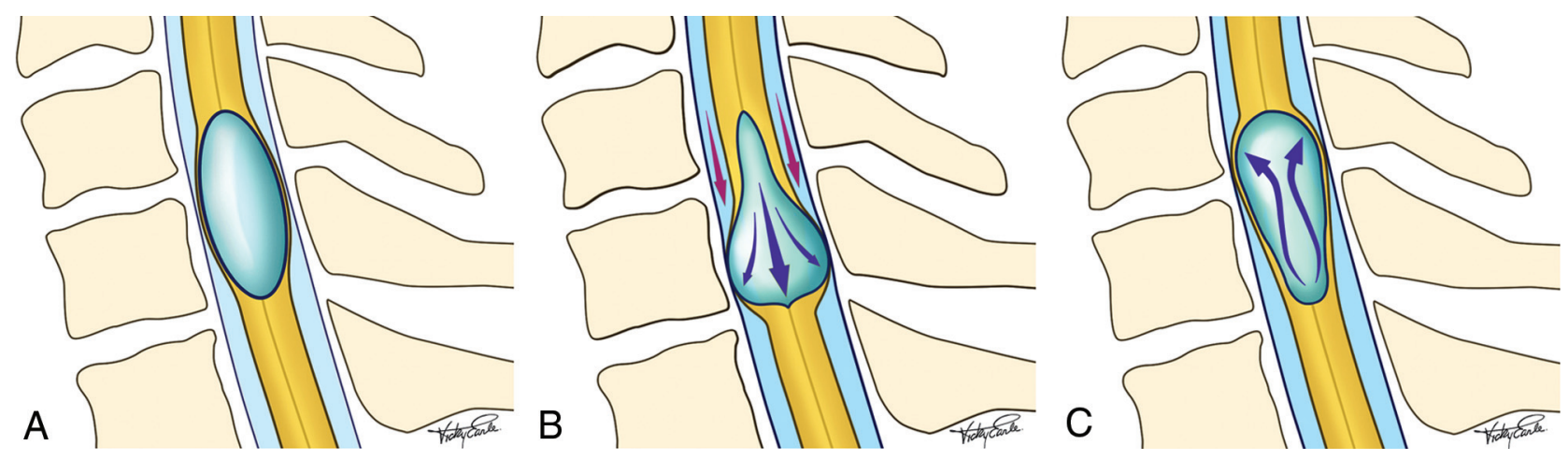

FIG 1. Diagram of the syrinx wall and fluid movement during the cardiac cycle. $A$, The syrinx "at rest" during late diastole with its classic ovoid shape. $B$, During systole, the superior portion of the syrinx is compressed, forcing a fluid jet caudally, which distends the inferior portion of the syrinx. C, During early diastole, the ballooned inferior portion of the syrinx recoils and forces the fluid rostrally to re-expand the superior portion of the syrinx. Images courtesy of Ms Vicky Earle (vearlemedicalart.com).

across the foramen magnum during Valsalva maneuvers in patients with hindbrain hernias and postulated that this craniospinal pressure dissociation, a force he called "suck," caused fluid to be pulled into the syrinx from the ventricle. The subsequent enlargement of the syrinx was thought to be due to fluid movement within the syrinx during Valsalva maneuvers, what he called "slosh."

Subsequent authors have highlighted the lack of communication between the syrinx and fourth ventricle and postulated that the fluid entered the syrinx from the spinal subarachnoid space. ${ }^{6,9,10}$ With the advent of dynamic MR imaging and intraoperative sonography, Oldfield et $\mathrm{al}^{6}$ proposed that the downward movement of the tonsils seen during systole caused a "pistonlike" effect, resulting in a CSF pressure wave that contracted the cord and forced fluid into it. Researchers argued, however, that if fluid pressure caused the cord to contract, it would be unlikely that any fluid could enter the cord. Grietz ${ }^{11}$ and Koyanagi and Houkin ${ }^{12}$ suggested that the syrinx fluid was extracellular in nature rather than CSF. Grietz proposed the "intramedullary pulse pressure theory," in which CSF moving abnormally rapidly past the cord caused a low pressure within the cord, promoting extracellular fluid (not CSF) to build up and eventually form a syrinx. ${ }^{11}$

We now know that various etiologies can produce syringes. The pathophysiology causing a fluid-filled cavity to form within the spinal cord is undoubtedly different following the absorption of a traumatic hematoma, the secretion of proteinaceous fluid from a neoplasm, or the altered CSF dynamics accompanying a hindbrain herniation. The pathophysiology underpinning the enlargement of syringes, however, may have a common theme. Across the years, imaging studies have helped elucidate the pathophysiology underpinning syrinx enlargement.

Initially, fluoroscopic images of dye within syringes were documented to pulsate with each heartbeat, and the rostral movement induced by cough was described as "impressive." 5 With the advent of MR imaging and quantification of spinal CSF pulsations, ${ }^{11}$ the noninvasive analysis of CSF hydrodynamics became possible. ${ }^{13} \mathrm{MR}$ imaging studies have measured the pulsatile motion of the cerebellar tonsils ${ }^{14}$ and lamina terminalis ${ }^{15}$ and have documented sinusoidal CSF flow linked to the cardiac cycle within syringes, along the spinal subarachnoid space, and across the foramen magnum. ${ }^{16,17}$ Most studies have used phase contrast techniques, which have allowed quantification of CSF velocities but with reduced anatomic resolution.

Our imaging was able to simultaneously demonstrate high anatomic resolution and fluid movement within the syrinx and spinal subarachnoid space. On-line Video 1 shows that during systole and concurrent with the downward displacement of the tonsils, the superior portion of the outer syrinx wall was initially impacted by the CSF systolic pulse pressure. This force distorted the shape of the syrinx, collapsing its upper portion and forcing the fluid within to jet inferiorly, impacting and ballooning the lower portion of the syrinx. During diastole, as the pressure gradient reversed, the distended lower portion of the syrinx recoiled and pushed fluid rostrally to expand the upper portion of the syrinx. The unexpected null artifacts extending through the syrinx and adjacent subarachnoid space (On-line Video 1) produced contrast in the syrinx fluid, enabling visualization of its movement. With each heartbeat, the syrinx walls were distorted unevenly, causing a jet of syrinx fluid to impact the inferior pole of the cavity. Slow caudal growth of the syrinx may follow 42 million such impacts during a year. Greater CSF pressure gradients follow Valsalva maneuvers, and asymmetric contraction of the syrinx may be responsible for the sudden rostral expansion described in the literature. ${ }^{18}$ Our study did not visualize the cord during a Valsalva maneuver. The current study provides direct visual confirmation of the CSF movement previously calculated by phase contrast MR imaging studies. Although the technique may not have had the necessary sensitivity to be definitive, there was no obvious transparenchymal movement of CSF visualized during our study, in keeping with the theories postulating that syrinx fluid accumulates from within the cord rather than from CSF being forced into it.

\section{CONCLUSIONS}

This novel imaging study of a cervical syrinx allowed simultaneous high-resolution visualization of syrinx fluid motion and the anatomy of the syrinx walls. The study supports the hypothesis that syrinx enlargement is due to the slosh of fluid with each heartbeat (and the Valsalva maneuver). The external asymmetric contraction of the rostral portion of the cord around the syrinx during systole caused a jet of fluid within the syrinx to extend caudally impacting and dilating the caudal portion of the syrinx. 
With diastole, the fluid moved more slowly to its original position as the dilated caudal portion of the syrinx returned to its original shape.

\section{REFERENCES}

1. Ollivier CP. Traité des Maladies de la Moelle Epinière: Contenant L'histoire Anatomique, Physiologique et Pathologique de Ce Centre Nerveux chez l'Homme. 2nd ed. Paris: Méquignon-Marvis père et fils; 1827:178-83

2. Harding BN, Copp AJ. Malformations. In: Grenfield JG, Graham DI, Lantos P, eds. Greenfield's Neuropathology. 7th ed. London: Arnold; 2002:443

3. Lotbinière AC. Historical considerations. In: Anson JA, Benzel EC, Awad IA, eds; AANS Publications Committee. Syringomyelia and the Chiari Malformations. Park Ridge: American Association of Neurological Surgeons; 1997:1-26

4. Gardner WJ, Angel J. The mechanism of syringomyelia and its surgical correction. Clin Neurosurg 1958;6:131-40 Medline

5. Williams B. On the pathogenesis of syringomyelia: a review. J R Soc Med 1980;73:798-806 Medline

6. Oldfield EH, Muraszko K, Shawker TH, et al. Pathophysiology of syringomyelia associated with Chiari I malformation of the cerebellar tonsils: implications for diagnosis and treatment. J Neurosurg 1994;80:3-15 CrossRef Medline

7. Wang DD, Martin KW, Auguste KI, et al. Fast dynamic imaging technique to identify obstructive lesions in the CSF space: report of 2 cases. J Neurosurg Pediatr 2015;15:519-23 CrossRef Medline

8. Storey P, Li W, Chen Q, et al. Flow artifacts in steady-state free precession cine imaging. Magn Reson Med 2004;51:115-22 CrossRef Medline

9. Alboulker J. Syringomyelia and intra-rachidian fluids, I: syringomyelia, 2: conceptions [in French]. Neurochirurgie 1979;25(suppl 1): 9-22 Medline

10. Milhorat TH, Miller JI, Johnson WD, et al. Anatomical basis of syringomyelia occurring with hindbrain lesions. Neurosurgery 1993; 32:748-54; discussion 754 CrossRef Medline

11. Greitz D. Unraveling the riddle of syringomyelia. Neurosurg Rev 2006;29:251-63; discussion 264 CrossRef Medline

12. Koyanagi I, Houkin K. Pathogenesis of syringomyelia associated with Chiari type I malformations: review of evidences and proposal of a new hypothesis. Neurosurg Rev 2010;33:271-84; discussion 284-85 CrossRef Medline

13. Enzmann DR, Pelc NJ. Normal flow patterns of intracranial and spinal cerebrospinal fluid defined with phase-contrast cine MR imaging. Radiology 1991;178:467-74 CrossRef Medline

14. Sharma A, Parsons MS, Pilgram TK. Balanced steady-state free-precession MR imaging for measuring pulsatile motion of cerebellar tonsils during the cardiac cycle: a reliability study. Neuroradiol 2012;54:133-38 CrossRef Medline

15. Reubelt D, Small LC, Hoffmann MH, et al. MR imaging and quantification of the movement of the lamina terminalis depending on the CSF dynamics. AJNR Am J Neuroradiol 2009;30:199-202 Medline

16. Rubin JB, Enzmann DR. CSF flow effects during MRI of the central nervous system. Magn Reson Annu 1988;147-87 Medline

17. Tanghe HL. Magnetic resonance imaging (MRI) in syringomyelia. Acta Neurochir 1995;134:93-99 CrossRef Medline

18. Bertrand G. Chapter 26: dynamic factors in the evolution of syringomyelia and syringobulbia. Clin Neurosurg 1973;20:322-33 Medline 